\title{
The Study of the Training Mode of Translation Professionals under the Guidance of Language Service Market
}

\author{
Wang Peng \\ Xi’an Fanyin University, Xi’an710105, China
}

Keywords: translation; language service; training mode

\begin{abstract}
Under the background of national strategy “The Belt and Road”, economy, culture and industries in China will usher in a rapid and stable development period, and the language service industry will also embrace great opportunities and challenges. Through the investigation and analysis of the current demand for the related talents in the industry, this paper, comparing with the traditional training mode of foreign language talents, puts forward an attempt to solve the training mode of language service personnel. The training mode of language service personnel should be guided by the market demand of the industry, especially to meet the market demand of local language service industry.
\end{abstract}

\section{Introduction}

The market demand of the language service industry in the globalization and information age has put forward higher requirements for the present translators. However, there is still a considerable gap in China between the requirements and the supply of translation talents as far as their competence and quantity are considered. It is undoubtedly an important way to narrow the gap by building a training mode of translation professionals guided by the language service market. This market-oriented training mode includes the integration between translator training mode and professional qualification system, the introduction of technology courses and project teaching, and the cooperation between universities and language service enterprises. It has a positive effect on meeting the needs of the industry and market, promoting the combination of production, teaching and research, standardizing the development of the industry and promoting the benign development of the translation industry.

\section{Domestic and International Research and Development}

The localization operation brought by transnational corporations in the market seeking investment constitutes the most stable and direct language service market demand. On the other hand, in the context of economic globalization, most of the core products and language-independent enterprises acquire non-strategic language services from the outside, which is the objective reason why the outsourcing of language services is rising rapidly with the increase of market seeking investment.

In recent years, Europe, North America and Asia have ranked among the top three countries in the global language service market, and these areas are also the most concentrated areas for foreign direct investment. As far as China is concerned, language service enterprises are concentrated in the eastern coastal areas with intensive foreign investment. The four provinces and cities of Beijing, Shanghai, Guangdong and Jiangsu account for $69.8 \%$ of the total national total, of which only Beijing and Shanghai account for 55.6\% (China translation association, 2012:21-22).

Language service include four major business areas: translation and localization service, language technology tool development, language teaching and training, and multi-language information consultation. The continuous progress of economic globalization and information technology has made the high quality language service become a reality. In the process of economic globalization, multinational corporations are the most active, dominant power in the international production system, and the most important service in the language service industry. Taking China as 
an example, foreign-funded enterprises account for $21.5 \%$ of the total number of Chinese language services, ranking first among all kinds of customer communities (China translation association, 2012:27). In China, the industrial position of language service industry was officially recognized for the first time in China international language service industry conference. Since 2012, the Chinese translation association and the Chinese translation industry development strategy institute have jointly released the annual Chinese language service development report, which is a sign that the language service has begun to be taken seriously by the government and academia.

\section{An Overview of the Global Language Services Industry}

According to Kamensensi consultants (CSA) statistics, in 2013 the global total of 27668 language services enterprises from 154 countries or regions, the total output value of the language service industry is expected to be $\$ 34$ billion 778 million. In the five years between 2008 and 2012, in addition to 2011, the language services market was annually growing at more than ten percent. The development of the global language services industry has the following characteristic.

In terms of turnover, Europe is the world's largest market for language services in 2013, with an estimated market share of 48.75 per cent, followed by North America (35.77 per cent) and Asia (11.38 per cent). By contrast, the market for language services in Oceania (2 per cent), Latin America and the Caribbean (1.8 per cent) and Africa (0.29 per cent) was almost negligible.

In 2013, $65.37 \%$ of the enterprises in the global language service industry were micro-enterprises, 26.52\% were small enterprises, $6.55 \%$ were medium-sized enterprises, and the small and medium-sized enterprises accounted for $98.44 \%$ of the total, while the proportion of large and large enterprises was only $1.61 \%$. It is worth noting that $94.53 \%$ of the world's language service companies are private enterprises, even among the 103 companies ranked in the top 100 in the global language service industry in 2013, the proportion of private enterprises is $89.3 \%$.

The global language service industry is highly fragmented, and the ability of a single enterprise to control the market is very weak and can only passively accept the price of a given language service. There are already two levels of differentiation in the industry. The overall strength and market influence of the top 10 enterprises are much higher than that of other enterprises, and the conditions for large-scale industrial concentration are already available.

With the diversity of service, the business practices of language service enterprises also experience important adjustments and changes: (1)The language service is professionally enhanced. In order to build the "core competence" of the enterprise for coping with the increasingly fierce market competition, more and more language service enterprises have concentrated the main business in the professional field. (2)Enterprises continue to open up new business growth points. While enhancing the professionalism of the enterprise, language service enterprises are also actively exploring new "high value-added" business areas.

\section{Opportunities and Challenges in the China's Language Service Industry}

China is the country with the largest number of foreign direct investment in developing countries. By the end of 2011, China has actually attracted 1164.392 billion US dollars in foreign investment, of which "market seeking" investment, which aims to open up the Chinese market, has a large proportion. With the rapid increase of comprehensive national strength, China has gradually become a big foreign investment country, with a total of 424.781 billion US dollars in foreign direct investment and 821.247 billion US dollars in foreign contracts. In recent years, China has also hosted a series of large-scale economic, trade, cultural and sports activities including the Olympic Games, the Asian Games, World Expo and the world horticultural exposition. The demand for language services generated by such large-scale international cultural and economic exchanges is a direct driving force for the rapid development of China's language service industry.

The diversification and refinement of the service division in the language service industry has prompted the "structural imbalance" in the language service talent market, that is, the lower end of the translation market is larger than the demand, while the high-end market, such as localization 
service, translation project management, cultural and scientific products translation, conference interpretation (simultaneous interpretation), is not available. It should be sought, and the "entry threshold" of the profession is very high.

The language service industry includes all the institutions engaged in multilingual information conversion and related services (2012:3, China Translation Association, etc.), covering the entire industrial chain related to language services. Although language service enterprises are in the "core layer" of the industry, the intellectual support from universities and research institutions, the upstream of the industry chain, is crucial to the overall competitiveness of the industry. As to translation teaching, colleges and universities in China has long focused more on theory than practice. The research on application of translation and talent training can not meet the needs of the development of language service industry, which is also a major reason for the "structural imbalance" in the talent market.

The main body of the language service industry in China is the private small and micro enterprises. According to statistics, enterprises with registered capital of less than 500,000 RMB account for $75.9 \%$ of the total, while those more than 10 million RMB only $1.6 \%$. Although the number of enterprises is large, the scale is small and the market competitiveness is weak. The problems that small enterprises face are lack of funds, talents, international resources and low investment in technology. It is difficult for them to introduce high value-added services and make innovation in business models. A large number of enterprises concentrate on the low-end translation business, and the severe competition caused by the "homogeneity" of the service content inevitably results in the decline in service prices and quality. Although China has the largest number of language service enterprises in the world, only 4 of them have entered the top 100 in the world in 2013, which is very disproportionate to the overall economic strength and the status of our country as a biggest developing country.

\section{The Role and Significance of Language-service Talent Training in the Construction of Translation Discipline}

As a new industry, language service industry has shown a flourishing trend in recent years, but the training of language service professionals in different fields can not keep pace with the development of the industry. Since economy and foreign cultural exchanges will require a large number of language service personnel, the language service industry can be developed as a market base for training language service professionals, and put these talents into the huge language service industry, greatly bringing economic and cultural development. The introduction of language service professionals can refine the mode of personnel training and further improve the training system of language talents. The research on language service industry and language service professionals will help to realize and promote the cooperation between school and enterprise, and further improve the teaching and research development model of "Production - Training - Research".

By investigating the language service industry, we can find out the basic trend of the demand for language service talents. This information has important reference value to grasp the development trend of the industry, develop new ways of cultivating talents and improve the quality of local public service, and also plays an active role in the diversified development of the translator-training mode in universities and colleges.

Colleges and universities for training professional talents in the language service industry must pay high attention to the development of the industry and actively adjust the training content and training methods, reasonably locating the professional direction, which is particularly important for these translation-professional schools. They should meet the needs of the social and economic development in the region and cultivate professionals in the specific fields by combining their own teaching resources, so as to meet the increasingly diversified and refined requirements by language services

The investigation and research on the talent demand of the language service industry will play a guiding role in improving the training program for the translation professionals in colleges and universities, and improve the practicability of the course setting of the translation profession. The 
enriched translation teaching not only improves students' translation competence but also enhances their consciousness of language service and market, and thus promotes the students to understand the professional environment and fit up into the industry. The model of "Production - Training Research" in the language service industry should be integrated more closely and reasonably. We will quicken the establishment of an exchange and cooperation platform between enterprises and universities for the training requirements and methods.

\section{Conclusion}

To sum up, when the language service industry continues to expand globally, and the professional requirements are constantly improved, the language service industry in China has also entered a rapid development period and the demand for high-level language service personnel in various industries is increasing year by year. So colleges and universities must formulate corresponding talents training strategies in accordance with the development of the industry, in order to meet the needs of the country's political, economic and cultural development.

\section{Acknowledgements}

Project1: “A Study and Analysis of Demand for Language Service Professionals in Shaanxi Province” supported by Shaanxi Province Education Department Special Science Planning Fund Project (No. 16JK2070)

Project2: "A Study of TAPs Translation Teaching Mode: Based on the Courses of Tourism Translation and English-Chinese Translation” supported by Xi’an Fanyi University (No. J16A02)

\section{References}

[1] Lv Yue \& Yan Lili. Translation Project Management [M]. Beijing: National Defense Press, 2014.

[2] Cui Qiliang. A Study on the Teaching Practice of Localization Project Management[J]. Shanghai Journal of Translators, 123(2), pp.58-62,2015.

[3] Wang Chuanying \& Lu Rui. A Study on Translation Norms in the Localization Service[J]. Shanghai Journal of Translators, 123(2), pp.63-69,2015.

About the Author: Wang Peng, (1976-), male, Master of Foreign Language Linguistics and Applied Linguistics; lecturer of Xi'an Fanyi University; research field: English teaching and translation studies.

Tel: 17792634503

E-mail: 16412436@qq.com 